\title{
Fiscal Pressures, Institutional Context, and Constituents: A Dynamic Model of States’ Arts Agency Appropriations
}

\author{
Douglas S. Noonan
}

[This paper originally appeared in Journal of Cultural Economics 31(4). The original publication is available at www.springerlink.com

Noonan, D. S. (2007). Fiscal pressures, institutional context, and constituents: a dynamic model of states' arts agency appropriations. Journal of Cultural Economics, 31(4), 293310. doi:10.1007/s10824-007-9052-9.]

\begin{abstract}
:
This report focuses on state government appropriations to state arts agencies (SAA), a primary figure in arts and cultural policy in the United States. A dynamic panel data estimator can identify the fiscal, institutional, and demographic determinants on SAA appropriations. Agency budgets are particularly sensitive to past appropriations, past state revenues and NEA grants, some demographic variables, party control of state government, and state budgeting rules. Federal funds attract, rather than crowd out, state appropriations. While the influence of some demographic variables may be shifting over time, income growth continues to explain much of SAA appropriations.
\end{abstract}

Keywords: arts, crowding out, dynamic panel data estimator, flypaper effect, public choice, public finance

1. Introduction

This paper examines a specific category of state government expenditures using variation over time and across states to identify the different influences on state budgeting decisions. The dynamic panel-data model allows testing of several hypotheses concerning the determinants of appropriations, namely fiscal, institutional, and 
demographic variables. The results add robust evidence to the empirical literature on state budget dynamics and shed light on an important and contentious state-level policy area.

This paper focuses on appropriations to state arts agencies (SAAs), a primary figure in arts and cultural policy in the United States. By 1974, all states had established an SAA. Although a few are much older, most SAAs were created largely to accept grants from the National Endowment for the Arts (NEA) after its creation in 1965 (Lowell 2004, Netzer 1978). The history and operations of SAAs have been thoroughly described elsewhere (Lowell 2004, Mulcahy 2002, Schuster 2002). SAA funding levels vary greatly across states. Per-capita SAA funding in 2004 ranged from $\$ 4.49$ per person in Hawaii to $\$ 0$ per person in Missouri, with an average of $\$ 0.99$ per capita. ${ }^{1}$ Over the past 36 years, Hawaii has the highest average per-capita SAA appropriations (\$4.48), while Texas has the lowest (\$0.19). Currently, about $81 \%$ of SAA budgets derive from state appropriations, plus only about 10\% from NEA grants (Olsen 2004). Millions of artists and over 20,000 organizations are funded by SAAs (Lowell 2004, NASAA 2005), making them a major force in public support of arts and culture.

In light of the recent fiscal crisis for states, public funding of the arts becomes even more intriguing. With SAAs accounting for almost 30\% of all public arts funding (Mulcahy 2002), arts and cultural programs may be particularly sensitive to conditions of state budgets. Yet the relationship is hardly reciprocal. On average, states allocate less than $0.05 \%$ of their annual budgets to SAAs (NASAA 2005). Often considered a luxury or 
nonessential publicly provided good, arts programs may be particularly vulnerable in times of recession. There is also disagreement over the constituency served by SAAs (Lowell 2004, Jacobs 2004). Previous observers have characterized the constituency of public arts funding as rather elite (Grampp 1989), narrow (Lewis and Brooks 2005), highly networked (Barsdate 2001), and diversifying (Schuster 2002). The nature of SAA constituencies should affect the SAAs’ susceptibility to budgetary shocks.

Little is known about the effects of socioeconomic and demographic factors, institutional context, and larger political and fiscal cycles on state-level arts expenditures. To explore these effects, the remainder of this paper is organized as follows. Section 2 reviews the relevant literature on state expenditures and SAAs budgets in particular. This section also sketches a theoretical model of SAA appropriations. Section 3 outlines the empirical estimation procedure, while Section 4 presents the results of the statistical analyses and hypotheses tests. Finally, a discussion of the results concludes.

\section{Literature Review and Theory}

Previous literature on state budget-setting has focused on overall levels of spending by state governments and occasionally on spending in broad categories. Besley and Case (2003) review much of this literature. They offer explanations for its inconsistencies and show some effects on spending of party competition, demographic composition, and institutional rules. They acknowledge that more research is needed to better understand these relationships, a challenge taken up by this paper. 
Sheffrin (2004) also recently summarizes much of this literature. He observes an emphasis on institutional rules and the role of political parties in models of state-level spending. Alt and Lowry $(1994,2000)$ show how differing party control of state governance can influence spending levels. While Democrats seek larger public budgets, Republicans cut revenues more in response to surpluses. Alt and Lowry, and others, have explored the role of balanced budget rules and other restrictions on state budgeting (see, for example, ACIR 1987, Poterba 1994, Craig et al. 1988, Maag and Merriman 2003).

Merrifield (2000) goes further in modeling the determinants of state expenditure and taxation. He stresses the role of institutional variables, beyond the simple median voter approach, in explaining state expenditures. Using data from 1980, 1985, and 1990, he estimates strong effects from voter preference variables and some institutional variables, although balanced budget requirements played a modest role. James Payne (1998) looks at fifty years of overall state revenues and expenditures and identifies the temporal relationship between taxing and spending in the states. By examining each state separately, he finds that revenue changes cause spending changes in about half of the states.

Other studies have analyzed expenditures in different state spending categories. For instance, Dye and McGuire (1992) characterize state spending patterns and offer stylized facts to explain spending pressures in several categories. McCarty and Schmidt (1997) use a vector autoregressive framework to show how broad state-level spending categories 
exhibit little crowding out. Increases in spending in one area are paid for via higher revenues rather than decreased spending in other areas.

This previous literature is largely empirical, and it tends to focus on general state-level expenditures or spending in major categories. Earlier research has tended to examine spending on major, priority areas for state budgets rather than spending on a particular agency. For example, Taggart (1989) investigates states' spending on corrections, tests several hypotheses about determinants of corrections funding, and observes spending levels to hinge closely on previous year's spending. Manwaring and Sheffrin (1997) explored state spending on education to test for effects of litigation and educational finance reform. Besley and Case (2003) model spending on family assistance and workers compensation, in addition to overall spending. This paper continues this line inquiry by further narrowing the scope of analysis: to the appropriations to a specific state program or agency.

Although a small program area, state arts agencies have attracted much attention. In their very early analysis of SAA appropriations, Hofferbert and Urice (1985) find SAAs an excellent “small-scale policy” area. Later, Netzer (1992) also explores determinants of SAA budget levels in 1987. Recently, Lewis and Rushton (forthcoming) examine budget determinants over 24 years in a basic fixed-effects model that emphasizes demographic influences. The following analysis exploits over 30 years (rather than just five for Hofferbert and Urice and just one for Netzer) in a considerably more robust statistical framework. 
A public choice approach to state program appropriations directs attention to institutional factors, relevant constituencies, and incentives facing decision-makers. The previous literature has highlighted important roles for balanced budget rules, party control of state governance, fiscal health and overall state income, and constituency strength.

Appropriations can also be expected to follow the growth in the constituency served, the number of actual or potential beneficiaries of a program.

A handful of economists have discussed SAAs in a public choice context. Grampp (1989) identifies the opportunity for and evidence of rent-seeking over arts funding. The possibility of arts agencies' "capture” at the hands of rent-seekers is emphasized by Lingle (1992), Peacock (1994), and Rizzo (1998). Frey (2000) and others have long wondered how publicly funded arts will alter the types of arts produced. Rushton (2001) notes the lack of inquiry into the process by which rent-seeking behavior translates into changes in policy. He questions the notion that arts funding results from elites lobbying for transfers, as arts programs may enjoy wide support from the public.

Besley and Case (2003) offer a useful model to apply to SAA appropriations. ${ }^{2}$ The appropriations $Y$ in state $i$ for year $t$ can be modeled as:

$$
Y_{i t}=f\left(C_{i t}, I_{i t}, T_{i t}\right)
$$

where vectors $C, I$, and $T$ represent political composition, institutional context, and economic and demographic characteristics affecting policy preferences, respectively. This relationship captures the potentially complex policy process that determines 
appropriations given political, social, and economic conditions. Besley and Case’s equation (2) can be adapted to an empirical model:

$$
Y_{i t}=\alpha_{i}+\beta_{t}+\psi C_{i t}+\omega I_{i t}+\gamma T_{i t}+\tau H_{i t}+\eta_{i t},
$$

where $H_{i t}$ is a vector of historical variables that includes lagged values of $Y$ and of other political controls. A state indicator is given by $\alpha_{i}$, a time indicator by $\beta_{t}$, and an error term by $\eta_{i t}$. For SAA budgets, primary components of the $C, I$, and $T$ vectors should include: general state revenues, party control of state governance, voter turnout, NEA grants, balanced budget restrictions, demographic composition, and economic conditions. The $H$ vector should include historical SAA appropriations, revenue levels, debt levels, and NEA grant levels. By empirically estimating this model, this paper contributes more evidence on the dynamics of state budgeting.

The paper's second major contribution is to provide new tests of several of the key claims of the literature on public funding of the arts. Most of these findings emphasize the role of fiscal pressures, institutional context, and constituency efficacy. Lowell (2004) argues that SAAs are particularly vulnerable to budget cuts during fiscal crises. Olsen (2004) and NASAA (2005) echo this by noting that fiscal conditions are the single largest determinant of SAA appropriations. Hofferbert and Urice (1985) claim that "policy norms" (measured by state-level spending in certain areas) explain much of the appropriations. Debate over government-funded arts follows closely along party and ideological lines, although links to actual policy decisions are less clear (Lewis and Brooks 2005, Lewis and Rushton forthcoming). Getzner (2002) tests for the influence of party control on public cultural expenditures in Austria and finds none. The location of 
the SAA within state governance (in cultural affairs department, in economic development department, etc.) may affect its political autonomy (Mulcahy 2002) and also its appropriations.

Beyond fiscal and institutional factors, constituencies are frequently expected to exert influence over agency budgets. Boles and Scheurer (2007) find strong influence of party, ideology, and constituency in arts votes by Representatives in the U.S. Congress. Lowell (2004) observes an important role of constituents in securing SAA funding, even while the SAA constituency appears to be changing over recent decades. Arts patrons, the educated (and urban) elite, supported SAA funding while actual and potential grantees conducted most lobbying efforts (Lowell 2004). Barsdate (2001) observes how advocacy networks developed alongside growing SAA budgets in the 1990s. On the other hand, Rushton (2003) suggests that recently declining public arts funding may be due to rising transaction costs, especially those associated with increasing cultural diversity in the nation. In that case, we might expect to see a general erosion or diffusion of the SAAs' constituency base over time. Hofferbert and Urice (1985) find that constituency variables do not play a large role in SAA appropriations, while agency age and NEA funding had some impact.

Revenue in the arts sector from other, possibly substitute, sources may also affect SAA appropriations. The interaction between private contributions and government funding of charitable organizations has received much attention in the literature (e.g., Ferris and West 2003, Brooks 2000, Steinberg 1993, Lindsey and Steinberg 1990). Some of it has 
focused specifically on the arts (e.g., Prieto-Rodrínguez and Fernández-Blanco 2006, Borgonovi and O’Hare 2004, Hughes and Luksetitch 1999). This “crowding out” literature emphasizes explaining how charitable contributions made or received respond to shifts in government funding. In the arts sector, the evidence is mixed at best (Brooks 2004, 2000). Borgonovi and O'Hare (2004) found NEA support and arts donations to be independent at a national level. Even if aggregate arts donations may not respond to public funding, the possibility that public funding responds to private support has been occasionally acknowledged in the arts and other sectors (Brooks 2000, A. Payne 1998). Where available data permit, proxies for private support of the arts can also be included.

\section{Empirical Model}

The empirical analysis here estimates a model of state SAA appropriations using panel data. The SAA budget level in a given state-year depends on the previous year's budget level, other past and current fiscal variables, and other exogenous variables. This model structure raises concerns about the autoregressive nature of the data and exogeneity of explanatory variables. Simple OLS may be biased and inconsistent because of the presence of an endogenous (lagged dependent) variable as a regressor.

The empirical model employed here considers annual SAA appropriations to be a function of several factors according to the following equation:

$$
Y_{i t}=\alpha_{i}+\beta_{t}+\rho Y_{i t-1}+\psi C_{i t}+\omega I_{i t}+\gamma T_{i t}+\tau H_{i t}+v_{i}+\eta_{i t} .
$$


$Y_{i t-1}$ represents the previous year's SAA appropriation in state $i$. As before, political composition, institutional context, and economic and demographic factors constitute vectors $C, I$, and $T$, respectively. $H_{i t}$ is a vector of historical variables other than $Y_{i t-1}$. A state-level disturbance term, $v_{i}$, is also included. There is a white noise error term, $\eta_{i t}$, which is assumed to be serially uncorrelated (i.e., $\mathrm{E}\left[\eta_{i t} \eta_{i s}\right]=0$, for any $t \neq s$ ). Similar dynamic specifications with a lagged dependent variable can be found in Manwaring and Sheffrin’s (1997) partial adjustment model of state school expenditures, McCarty and Schmidt’s (1997) VAR model of state expenditures by category, and Getzner’s (2002) model of public cultural expenditures in Austria.

The estimation strategy employed here uses Arellano and Bond’s (1991) dynamic paneldata estimator. Even with serially uncorrelated errors $\eta_{i t}$ in (1), right-hand side regressor $Y_{i t-1}$ remains correlated with $v_{i}$, leaving ordinary estimators biased and inconsistent. Taking the first differences, equation (1) becomes:

$$
\begin{aligned}
& Y_{i t}-Y_{i t-1}=\beta+ \rho\left(Y_{i t-1}-Y_{i t-2}\right)+\psi\left(C_{i t}-C_{i t-1}\right)+ \\
& \omega\left(I_{i t}-I_{i t-1}\right)+\gamma\left(T_{i t}-T_{i t-1}\right)+\tau\left(H_{i t}-H_{i t-1}\right)+\eta_{i t}-\eta_{i t-1} .
\end{aligned}
$$

First-differencing equation (1) eliminates $v_{i}$ but leaves the difference in lagged $Y_{i t}$ correlated with the error term via $\eta_{i t-1}$. Many instruments are available to estimate (2), based on moment conditions that follow from standard assumptions that $\eta_{i t}$ is uncorrelated with $Y_{i 0}, v_{i}$, and other $\eta_{\text {is }}$ for all $s \neq t$ (Ahn and Schmidt 1995). The Arellano and Bond estimator uses lagged levels of the dependent and predetermined variables, as well as differences in strictly exogenous variables, as instruments. The validity of using 
lagged values of $Y_{i t}$ as instruments for differenced equations for later periods hinges on the moment conditions implied by assuming $\eta_{i t}$ to be serially uncorrelated.

Estimating (2) using lags of the endogenous $(Y)$ and exogenous $(C, I, T)$ and predetermined $(H)$ variables via GMM yields estimates for $\beta, \rho, \psi, \omega, \gamma$, and $\tau$. Instruments for (2) derive from lagged levels of endogenous and predetermined variables and differences of strictly exogenous variables from all time periods. Notice that, for the differenced equation in (2), the instruments must come from lags at least three periods prior (i.e., for $H_{i t-s}, s \geq 3$ ). The construction in (2) differences out the time-invariant state fixed effects. By constructing $T_{i t}$ carefully, however, state fixed-effects on changes in levels of $Y_{i t}$ (but not state fixed-effects on levels of $Y_{i t}$ ) can be identified. ${ }^{3}$ Moreover, the constant term in the GMM estimation can be replaced with a constant time trend, interpreted as annual change in $Y_{i t}$, ceteris paribus.

Several specification tests are employed for the estimation of equation (2). Tests for the lack of serial correlation and possibly over-identifying restrictions, following Arellano and Bond (1991), are needed to verify whether the estimator is consistent. First, a second-order autocorrelation test $\left(m_{2}\right)$ is performed based on average covariance in the residuals. The consistency of Arellano and Bond's GMM estimator depends on $\mathrm{E}\left[\left(\eta_{i t}-\eta_{i t-1}\right)\left(\eta_{i t-2}-\eta_{i t-3}\right)\right]=0$ even when $\mathrm{E}\left[\left(\eta_{i t}-\eta_{i t-1}\right)\left(\eta_{i t-1}-\eta_{i t-2}\right)\right] \neq 0$. Second, a Sargan test of over-identifying restrictions is performed. Large statistics for these tests suggests that the assumption of no serial correlation may be inappropriate for this sample. A small value for Sargan's s lends support to the validity of the instruments used in this approach. 
Private arts support might belong in equation (1), yet its possible endogeneity must be addressed. Two approaches are found in the crowding out literature, although they treat government funding as endogeneous. First, inspired by Brooks (2000), last year's private arts support can enter (1) as part of $H$. His intuition holds: if government reacts to private contributions, then the previous year's contributions are the most observable (and this year's appropriations cannot affect last year's private contributions). Second, inspired by Abigail Payne (1998), this year’s private arts support enters as endogenous regressor. The Arellano-Bond estimator instruments for the endogenous private support variable as outlined above.

[Table 1 about here]

The state-level variables in this panel dataset are listed in Table $1 .{ }^{4}$ Various sources provide the data for the empirical estimation. The data range from 1969 to 2002, with some missing values (generally for those states without SAAs prior to 1974). Historical fiscal variables include SAA appropriations, state revenue, state debt, and NEA grants. Political composition and institutional variables include dummy variables for different situations of party control of state government, voter turnout, strictness of state balanced budgeting rules, the year of SAA establishment, and fixed effects of years in a four-year presidential term. Economic and demographic factors consist of population, density, race, age, education, and income variables. 
To examine the role of substitute sources of support for the arts, two proxies for private support for the arts are considered. First, an indicator of state-level personal income deriving from arts-related industries is constructed. ${ }^{5}$ This variable captures earned and charitable income, includes some non-arts income because of the crude industry classifications, and spans 1969-2002. Second, a measure of charitable contributions received by arts organizations is available for 1989-2002 from the National Center for Charitable Statistics (NCCS). ${ }^{6}$ This variable, however, includes private gifts and government grants to arts, culture, and humanities public charities.

Perhaps surprisingly, these indicators of private arts support had virtually no impact on the various models considered below. In no case was the private arts support variable significant at the $10 \%$ level. This holds for various constructions of both variables: artsrelated income or contributions to arts charities. This holds whether the variable entered as a lagged exogenous or endogenous variable. Most importantly given this analysis's focus, including the private arts support variable had only minor effects, if any, on the other coefficients. This weak role for private arts support may be due to data limitations (e.g., short timespan, poor proxies for substitute support), independence of SAA appropriations from private arts support, or something else. Because this analysis cannot reject the hypothesis that SAA appropriations are independent of private arts support and for simplicity, this variable is omitted from the estimations below.

\section{Results}


Table 2 depicts the results of the dynamic panel-data estimation. Each model is estimated using the Arellano-Bond one-step estimator with asymptotic standard errors robust to general time series and cross-section heteroskedasticity. The instruments include all lagged levels of $S A A_{t-2}$, the lagged levels of the fiscal variables, and all the first differences of the remaining regressors. The models in Table 2 explain most of the variation over time and across states in SAA appropriations. Model 1 is the base model, with Model 2 adding state fixed effects and Model 3 adding additional $T$ variables. The reported test statistics, the $m_{2}$ and Sargan's test, are suitably close to zero in all models to not imply that the model is misspecified. Serial correlation in the errors is not evident. The choice of instruments and the Arellano and Bond approach appear to be appropriate for these data.

As expected, lagged appropriations are strong predictors of current funding levels. The effect of state revenue on SAA funding differs depending on whether state-specific SAA growth rates are allowed. The current and previous two years of state revenue lack significance, jointly and individually, in Model 1. With state fixed effects, Model 2 shows significant positive effects from revenue in the current and previous two periods. Recent state debt levels adversely affect SAA funding, at least when state fixed effects are included. Higher debt levels from two years prior, however, are positively associated with SAA appropriations. NEA grants attract more state government appropriations to SAAs, both in the present year and two years hence. 
State demographic variables' effects also depend on whether state fixed effects are incorporated. Without controlling for state fixed effects, population and density appear positively and weakly related to SAA appropriations. Model 2 shows strong positive effects of population density on SAA appropriations. Race lacks much explanatory power. More youthful populations and more elderly populations, however, tend to receive lower SAA funding. Education levels appear unrelated to SAA funding, perhaps reflecting the considerable measurement error in the imputed College variable. Model 1 estimates the income elasticity of SAA funding as 0.78 .

\section{[Table 2 about here]}

Political context variables also play an important role. Party control of state governance is closely associated with SAA appropriations under all models. Relative to the omitted category of divided state government with a Democratic governor, SAA appropriations rise faster under divided government with a Republican governor. Moreover, states with divided houses of the legislature and a Republican governor also have higher SAA appropriation growth rates on average. In short, Republican governors bode well for SAA funding only if the government stays divided. Over time, funding appears to be in steady decline. Each year brings a $2-6 \%$ reduction in SAA budgets, all else equal. An electoral cycle effect is evident here, with appropriations dipping in the first year of a presidential term. Higher voter turnout is associated with lower budgets, although this effect is not statistically significant. Newer SAAs have slightly faster budget growth

rates. $^{7}$ Stringency of state balanced budget rules also exhibits a modest, positive effect on SAA appropriations growth rates. 
Model 2 in Table 2 shows the estimated model after controlling for state fixed-effects. Table 3 offers more insight into the individual states' effects. This might be taken as a measure of states' time-invariant, omitted "SAA friendliness." To make interpreting the state-specific effects more straightforward, the estimates in Table 3 derive from a version of Model 2 that omits time-invariant variables (Origin Year and BalanceBudg). These effects range from $-5 \%$ to $2 \%$ (growth rates in SAA appropriations), relative to the omitted category of Nebraska. Vermont and Florida’s SAA appropriations exhibited 5\% slower growth rates, while Nevada and Indiana were marginally faster. The rightmost column represents the departmental location of the SAA within state government as of 2004. It appears that SAA growth rates do not vary systematically across the departmental location of agencies.

\section{[Table 3 about here]}

Several hypotheses related to others’ observations about public arts funding can also be tested. First, the hypothesis that NEA grants complement SAA budgets cannot be rejected, as it appears that states receiving larger NEA grants also appropriate more to their SAAs. ${ }^{8}$ Second, the influence of political composition variables on SAA budgets is apparent. The hypothesis that SAA budgets grow more under Democratic leadership, perhaps because Democrats tend to push for larger state spending, appears only partly true. The results for Models 1 and 2 indicate larger SAA budgets when Republicans control the governorship but not also both houses of the legislature. Third, the proposition that institutional context affects SAA funding finds some support. The 
hypothesis that some states are more arts-friendly than others can be tested using Model 2, a conclusion that appears warranted for at least a few states. The existence of a departmental location effect is not evident. ${ }^{9}$ Stricter budget rules are associated with faster growth in SAA appropriations, rather than slower growth as Barsdate (2001) suggests. The inability of SAA funding to keep pace with inflation presents another challenge for SAA budgets and SAA supporters (who do not appear to be building an increasingly effective lobby, at least relative to other interests).

Table 2 also helps identify the role of different constituencies in predicting appropriations. The significance of population density implies the urban core constituency has some effect. The affluent also seem to have some success in affecting SAA budget growth. Racial composition of states, however, appears mostly unrelated to SAA appropriations. Moreover, the share of the population that is young or elderly is inversely related to SAA appropriations. From this analysis, the middle of the age distribution positively affects appropriations rather than the young or elderly constituents. Table 2 offers little support for those tying SAA appropriations to arts education initiatives or to agency capture by old, white art lovers. Appropriations are closely tied to income, however. Education levels, which are commonly found to be strong predictors of support for the arts (e.g., Peterson et al. 2000), lack a significant relationship in Table 2. This may be due to College being an inadequate measure of education. The results for income and education are roughly similar to Lewis and Rushton (forthcoming). The relationship between education and SAA funding is worth exploring in future research. 
Hypotheses about a changing constituency base over time can also be tested. Rushton (2003) suggests that increasing diversity may lead to declining public support for the Arts. Lowell (2004) also emphasizes the SAAs' shifting constituency base. To examine whether various constituencies' influence on SAA appropriations has changed over time, Model 1 was estimated with each of the demographic variables also interacted with the year. The hypothesis that these interaction terms jointly have no effect can be rejected $\left(\chi^{2}(8)=45.92\right)$. Taken individually, no time trend is evident in the influence of population, education, or income. On the other hand, Youth and Elders exhibit significant negative effects in this model. This negative effect is attenuated over time, so much so that effect on appropriations becomes positive by 1991and 1981 for Youth and Elders, respectively. This approach also detects a significant positive effect of Density and Black on appropriations, but this effect is also fading over time. The relationships between SAAs and their constituents do appear to be changing over time.

Finally, income and revenue elasticities can be investigated in more detail. Several observers have noted the possibility that SAA appropriations may do well in times of economic growth, but suffer disproportionately in recessions. This possible asymmetry is tested using these data in Model 3. New variables are constructed for the three state revenue variables in Model 1 and for the Income variable. These are the same firstdifferenced variables interacted with a dummy variable indicating whether the change was positive, effectively censoring negative changes to equal zero. Incorporating these variables into Model 3 allows for different elasticities for revenue or income growth than for their declines. The revenue growth elasticities are not individually significantly 
different from zero, similar to Model 1 , except the elasticity of Revenue $t_{t-2}$ during declines becomes significant. It seems that, when revenues fall by $10 \%$, SAA appropriations two years later are expected to fall by 1.2\%. (In times of revenue growth, a 10\% revenue increase is associated with a $1.3 \%$ appropriations cut two years later, although this elasticity is not significantly different from zero.) The income growth coefficient ( $\beta=$ $0.76)$ is significantly different from zero $(\mathrm{z}=2.17)$. Asymmetry in the income elasticity appears, where SAA appropriations do not significantly fall with income declines but have an elasticity of $1.09(\mathrm{z}=3.41)$ when incomes rise. Although there may be a modest and asymmetric relationship between lagged revenues and SAA appropriations, the income elasticity exceeds unity for periods of income growth and is quite small for periods of declining income.

The income elasticity estimates obtained here compare fairly well with some other commonly cited income elasticity measures for the arts. The estimate in Model 1 resembles a general relationship between income and willingness-to-pay for arts programs. In the sample of original contingent valuation studies identified in Noonan (2004), the average WTP rises $7.4 \%$ for each $10 \%$ increase in the mean income of the study sample. ${ }^{10}$

These results lend little support to those who fear that SAAs fare particularly badly during recessions. SAA appropriations are indeed sensitive to fluctuations in state revenues, and the effects are felt for several years, but there is scant evidence that the effects are significantly worse when revenues decline. The lagged effect of revenue 
changes on SAA appropriations when revenue falls arguably compares favorably to the negative (but insignificant) revenue effect on appropriations when revenue rises.

\section{Discussion}

In summary, the appropriations to SAAs follow a somewhat predictable pattern. Previous year's funding levels and other fiscal variables account for much of the variation in SAA appropriations. In particular, general state revenues from up to two years ago affect current SAA funding, and NEA grants complement state arts appropriations. Statewide demographic trends also guide SAA funding. Having fewer youths and elderly predicts larger SAA budgets, just as rising prosperity is a driving force in rising SAA appropriations. The party composition of state governance plays an important, but complex, role as well. Divided state governments bode well for SAA funding. Temporal effects are strong also, with SAA budget growth suffering a downward time trend and cyclical declines associated with the first year of presidential terms.

These findings significantly add to our understanding of SAA budgeting processes. As reviewed in Section 2, many previous commentators have asserted or suspected determinants of SAA funding. Table 4 lists a selection of these expected relationships alongside the evidence from the present analysis. Some claims find support, while others do not. Perhaps most importantly, the results indicate that NEA funding leverages even more state appropriations. Crowding out from federal aid is not observed. Moreover, 
SAAs are sensitive to shocks to overall state budgets, and the effects of changes in general revenues ripple through SAA budgets for several years. The claim that SAA budgets are particularly vulnerable during state fiscal crises finds only limited support here. Revenue declines have a significant, negative effect on SAA appropriations with a two-year lag, but appropriations may not fare better following revenue gains. Party politics matters, but it is not as simple as Republicans seeking to cut SAA budgets. The growth in SAA budgets over time owes greatly to the growth in overall state budgets and increasing prosperity - both of these strong trends have outweighed the underlying negative growth rate of SAA budgets.

\section{[Table 4 about here]}

Several variables that might have been expected to influence SAA funding do not. Voter turnout and racial composition show no significant relationships even when state effects are included. Surprisingly, education levels are not positively related. More disconcerting for arts education advocates, perhaps, is the negative relationship between youthful populations and SAA appropriations. A few states stand out as especially strong or weak funders of their SAAs. Finally, the locus of the SAA within state government lacks a clear influence on state governments' funding growth rates.

The empirical analysis demonstrates the impact of particular fiscal pressures, institutional rules, and constituents on state agency funding over the past three decades. The results bring robust empirical evidence to debates concerning public arts funding via SAAs, a 
major source of direct government support for the arts in the United States. Agency budgets are particularly sensitive to past appropriations, past state revenues and NEA grants, some demographic variables, party control of state government, and state budgeting rules. While the influence of some demographic variables may be shifting over time, income (and income growth in particular) continues to explain much of SAA appropriations. From a public policy standpoint, these findings offer a useful vantage to assess public arts funding. Fiscal pressures, institutional rules, and changing constituencies all play important roles in state arts agency funding. 


\section{Notes}

${ }^{1}$ Dollar figures throughout this paper are given in 2000 US\$, unless otherwise noted.

${ }^{2}$ Merrifield's (2000) model of spending might also be used here. He models SPEND = f(marginal utility of public office, marginal perceived benefits of spending, marginal perceived costs of spending, income, tastes, decision-making constraints). Such an approach can lead to comparable empirical tests.

${ }^{3}$ Specifically, partition $T_{i t}$ into $\left(T_{1 i t} T_{2 i t}\right)$ with state fixed-effects $T_{1 i t}=T_{1 i s}$, for all $t \neq s$. Let the corresponding vector of parameters for $T_{1 i t}$ vary over time at a constant rate. Estimating (2) with state fixed-effects $T_{1 i t}$ reveals parameters $\gamma_{1}$, which correspond to state-specific rates of change.

${ }^{4}$ Additional variables were tested in this model, but their role was found to be minimal or not enough years were available. They were excluded for the sake of parsimony. These variables include public school expenditures, percent Hispanic, additional age categories, gross state product, gross state product from federal sources, and additional variables describing state budgeting rules.

5 The variable ArtsIncome is estimated from the Bureau of Economic Analysis (BEA) annual state estimates for personal income (http://www.bea.gov/regional/spi/) for 19692000. Two SIC categories are summed: “amusement and recreation services” (835), and “museums, botanical, zoological gardens” (865). Values for 2001 and 2002 are imputed based on a GLS regression using state fixed effects, the BEA's estimates for similar NAICS categories, and a time trend. Details available upon request. The log of real ArtsIncome is used. 
6 This alternate ArtsIncome variable derives from the NCCS's Core Files containing financial information on reporting public charities since annual reporting began in 1989 . The log of total real contributions, gifts, and grants reported for “Arts, Culture, and Humanities” charities in each state is used. Unfortunately, NCCS does not report nongovernmental contributions separately.

${ }^{7}$ Because the Origin Year and BudgetBal variables are time-invariant, they must enter the model already first-differenced. Thus, their estimated coefficients must be interpreted differently than the others. For a dependent variable that is the first-difference in log SAA appropriations, the coefficient for Origin Year implies a $0.26 \%$ higher growth rate for an SAA founded in 1975 rather than 1965.

8 The observed contemporaneous elasticity (0.13) is particularly interesting given the matching requirements of NEA grants (Lowell 2004). The share of SAA budgets from NEA grants dipped below 50\% decades ago. A modest flypaper effect (Hines and Thaler 1995) appears, as the median effect of an additional NEA dollar on SAA appropriations is to boost it by $\$ 0.39$ in 2004 .

9 Adding fixed effects for SAA locations (state, culture, economic development, and independent) to Model 1, treating each variable as exogenous without taking first differences, yields effects not statistically significantly different from zero when tested individually and jointly.

10 Of the 33 studies, 12 report both WTP and mean sample incomes. The log of the average WTP (median when reported, otherwise mean) was regressed upon the log of the mean sample income, all in 2002 US\$. Because studies typically report valuation estimates for multiple goods, samples, or methods, a random effects regression is 
employed to allow for study-specific error terms. The regression with $\mathrm{N}=42$ yields a $\mathrm{R}^{2}=0.37$, income elasticity of 0.737 , and a robust standard error of 0.14 . 


\section{References}

ACIR (Advisory Commission on Intergovernmental Relation). 1987. Fiscal Discipline in the Federal System: National Reform and the Experience of the States. A-107. July 1987. Washington, DC: ACIR.

Ahn, Seung C. and Peter Schmidt. 1995. "Efficient Estimation of Models for Dynamic Panel Data.” Journal of Econometrics. 68: 5-28.

Alt, James E. and Robert C. Lowry. 1994. “Divided Government, Fiscal Institutions, and Budget Deficits: Evidence from the States.” American Political Science Review. 88(4): 811-828.

Alt, James E. and Robert C. Lowry. 2000. “Political Institutions and Policy Choices: Evidence from the United States.” Journal of Politics. 62(4): 1035-1069.

Arellano, Manuel and Stephen Bond. 1991. “Some Tests of Specification for Panel Data: Monte Carlo Evidence and an Application to Employment Equations.” Review of Economic Studies. 58(2): 277-297.

Barsdate, Kelly. 2001. “The State Arts Agency Policy Environment.” University of Chicago Cultural Policy Center: Working Paper 5.

BEA (Bureau of Economic Analysis). 2005. Regional Economic Information System. Table CA1-3. April 2005. Available online at: http://www.bea.doc.gov/bea/regional/reis/ . Last accessed 24 August 2005.

Besley, Timothy and Anne Case. 2003. "Political Institutions and Policy Choices: Evidence from the United States.” Journal of Economic Literature. 41(1): 7-73. 
Boles, Janet K. and Katherine K. Scheurer. 2007. “Beyond Women, Children, and Families: Gender, Representation, and Public Funding for the Arts.” Social Sciences Quarterly. 88(1): 39-50.

Borgonovi, Francesca and Michael O’Hare. 2004. “The Impact of the National Endowment for the Arts in the United States: Institutional and Sectoral Effects on Private Funding.” Journal of Cultural Economics. 28(1): 21-36.

Brooks, Arthur C. 2004. “The Effects of Public Policy on Private Charity.” Administration \& Society. 36(2): 166-185.

Brooks, Arthur C. 2000. “Is There a Dark Side to Government Support for Nonprofits?” Public Administration Review. 60(3): 211-218.

Craig, Steven G. and Joel W. Sailors. 1988. "State Government Purchases in a Federalist Economy.” Public Choice. 56: 121-130.

Dye, Richard F. and Therese J. McGuire. 1992. "Sorting State Expenditure Pressures.” National Tax Journal. 45(3): 315-329.

Ferris, J. Stephen and Edwin G. West. 2003. "Private Versus Public Charity: Reassessing Crowding Out from the Supply Side.” Public Choice. 116(3-4): 399417.

Frey, Bruno S. 2000. Arts and Economics: Analysis and Cultural Policy. Berlin: Springer.

Getzner, Michael. 2002. “Determinants of Public Cultural Expenditures: An Exploratory Time Series Analysis for Austria.” Journal of Cultural Economics. 26(4): 287306.

Grampp, William D. 1989. “Rent-seeking in Arts Policy.” Public Choice. 60: 113-121. 
Hines, James R. and Richard H. Thaler. 1995. “The Flypaper Effect.” Journal of Economic Perspectives. 9(4): 217-226.

Hoffebert, Richard I. and John K. Urice. 1985. “Small-Scale Policy: The Federal Stimulus versus Competing Explanations for State Funding for the Arts.” American Journal of Political Science. 29: 308-329.

Hughes, Patricia Nold, and William Luksetich. 1999. “The Relationship among Funding Sources for Art and History Museums.” Nonprofit Management and Leadership. 10(1).

Jacobs, Leonard. 2004. “RAND: State Arts Agencies Too Weak.” Back Stage. 17 June 2004. Available online: http://www.backstage.com/backstage/news/article_display.jsp?vnu_content_id=1 $\underline{000533878}$ Last accessed on 18 August 2005.

Lewis, Gregory B. and Arthur C. Brooks. 2005. “A Question of Morality: Artists’ Values and Public Funding for the Arts.” Public Administration Review. 66(1): 8-17.

Lewis, Gregory B. and Michael Rushton. forthcoming “Understanding State Spending on the Arts: 1976-1999.” State and Local Government Review. 39.

Lindsey, Lawrence and Richard Steinberg. 1990. “Joint Crowdout: An Empirical Study of the Impact of Federal Grants on State Govern ment Expenditures and Charitable Donations.” National Bureau of Economic Research Working Paper \#3226.

Lingle, Christopher. 1992. "Public Choice and Public Funding of the Arts.” In Ruth Towse and Abdul Khakee, eds., Cultural Economics. Berlin: Springer-Verlag. 
Lowell, Julia F. 2004. State Arts Agencies 1965-2003: Whose Interests to Serve? Santa Monica, CA: RAND Corporation.

Maag, Elaine and David Merriman. 2003. “Tax Policy Responses to Revenue Shortfalls.” State Tax Notes, 4 August 2003. Vol. 29. 363-373.

Manwaring, Robert L., and Steven M. Sheffrin. 1997. "Litigation, School Finance Reform, and Aggregate Educational Spending.” International Tax and Public Finance. 4: 107-127.

McCarty, Therese A. and Stephen J. Schmidt. 1997. “A Vector-Autoregression Analysis of State-Government Expenditure.” American Economic Review. 87(2): 278-282. Merrifield, John. 2000. “State Government Expenditure Determinants and Tax Revenue Determinants Revisited.” Public Choice. 102(1-2): 25-50.

Mulcahy, Kevin V. 2002. “The State Arts Agency: An Overview of Cultural Federalism in the United States.” Journal of Arts Management, Law, and Society. 32(1): 6780.

NASAA (National Assembly of State Arts Agencies). 2004. State Arts Agency Public Funding Sourcebook. Washington, DC: NASAA.

NASAA. 2005. "State Arts Spending Holds Steady.” NASAA press release. 17 June 2005. Available online: http://www.nasaa-arts.org/nasaanews/legapprop05/press_rel.pdf Last accessed on 18 August 2005.

NCSL (National Conference of State Legislatures). 2004.

Netzer, Dick. 1978. The Subsidized Muse: Public Support for the Arts in the United States. New York: Cambridge University Press. 
Netzer, Dick. 1992. "Cultural Policy in an Era of Budgetary Stringency and Fiscal Decentralization: The U.S. Experience.” In Ruth Towse and Abdul Khakee, eds., Cultural Economics. Berlin: Springer-Verlag.

Noonan, Douglas S. 2004. "Valuing Arts and Culture: A Research Agenda for Contingent Valuation.” Journal of Arts Management, Law, and Society. 34(3): 205-221.

Olsen, Eric. 2004. Legislative Appropriations Annual Survey, Fiscal Year 2004. Washington, DC: NASAA.

Payne, A. Abigail. 1998. "Does the Government Crowd-Out Private Donations? New Evidence from a Sample of Non-Profit Firms.” Journal of Public Economics. 69: 323-345.

Payne, James E. 1998. “The Tax-Spend Debate: Time Series Evidence from State Budgets.” Public Choice. 95: 307-320.

Peacock, Alan. 1994. "The Design and Operation of Public Funding of the Arts: An Economist’s View.” In Cultural Economics and Cultural Policies. Edited by Alan Peacock and Ilde Rizzo. Dordrecht: Kluwer Academic Press: 167-84.

Peterson, Richard A., Pamela C. Hull, and Roger M. Kern. 2000. Age and Arts Participation: 1982-1997. Santa Ana, CA: Seven Locks Press.

Poterba, James M. 1994. “State Responses to Fiscal Crises: The Effects of Budgets Institutions and Politics.” Journal of Political Economy. 102(4): 799-821. Prieto-Rodríiguez, Juan and Víctor Fernández-Blanco 2006. “Optimal Pricing and Grant Policies for Museums.” Journal of Cultural Economics. 30(3):169-181. 
Rizzo, Ilde. 1998. "Heritage Regulation: A Political Economy Approach.” In Does the Past Have a Future? The Political Economy of Heritage, Alan Peacock, ed. London: Institute of Economic Affairs.

Rushton, Michael. 2001. “A New Institutional Economics Approach to the Organization of State and Provincial Arts Councils.” University of Chicago Cultural Policy Center: Working Paper 8.

Rushton, Michael. 2003. "Cultural Diversity and Public Funding of the Arts: A View from Cultural Economics.” Journal of Arts Management, Law, and Society. 33(2): 85-97.

Schuster, J. Mark. 2002. "Sub-National Cultural Policy--Where the Action Is: Mapping State Cultural Policy in the United States.” International Journal of Cultural Policy. 8(2): 181-196.

Sheffrin, Steven M. 2004. "State Budget Deficit Dynamics and the California Debacle.” Journal of Economic Perspectives. 18(2): 205-226.

Steinberg, Richard. 1993. "Does Government Spending Crowd Out Donations? Interpreting the Evidence.” In The Nonprofit Sector in the Mixed Economy. Edited by Avner Ben-Ner and Benedetto Gui. Ann Arbor, MI: Univ. of Michigan Press, 99-125.

Taggart, William A. 1989. “A Note on Testing Models of Spending in the American States: The Case of Public Expenditures for Corrections.” The Western Political Quarterly. 42(4): 679-690. 
Table 1: Variable Descriptions and Sources

\begin{tabular}{|c|c|c|c|c|}
\hline Variable & Mean & Std.Dev & Description & Source \\
\hline $\mathrm{SAA}_{\mathrm{t}}$ & 14.25 & 1.50 & $\log$ of real SAA appropriations in year $t$ & NASAA (2004) \\
\hline Revenue $_{\mathrm{t}}$ & 15.83 & 1.00 & log of real general revenues in year $t$ & (a), various years \\
\hline Debt $_{t}$ & 15.09 & 1.23 & log of real debt outstanding in year $t$ & (a), various years \\
\hline $\mathrm{NEA}_{\mathrm{t}}$ & 13.15 & 0.38 & log of real NEA grants to state & NASAA (2004) \\
\hline Population & 14.88 & 1.03 & $\begin{array}{l}\text { log of population (estimates for intercensal } \\
\text { years) }\end{array}$ & (b) \\
\hline Density & 0.24 & 0.32 & Population per acre & (a), 2005 \\
\hline Black & 0.11 & 0.12 & proportion of population that is Black & (b) \\
\hline Other & 0.04 & 0.09 & $\begin{array}{l}\text { proportion of population that is nonwhite, and } \\
\text { non-Black }\end{array}$ & (b) \\
\hline Youth & 0.31 & 0.04 & proportion of population that is aged $\leq 19$ & (b) \\
\hline Elders & 0.15 & 0.18 & proportion of population that is aged $>65$ & (b) \\
\hline College & 0.19 & 0.06 & $\begin{array}{l}\text { proportion of population aged > } 25 \text { with } \\
\text { Bachelor's degree or higher, imputed }\end{array}$ & (b), (c) \\
\hline Income & 9.99 & 0.22 & log of real personal income (per capita) & BEA (2005) \\
\hline RGovGrid & 0.07 & 0.26 & $\begin{array}{l}\text { dummy for Republican governor, divided } \\
\text { legislature }\end{array}$ & (a), various years \\
\hline DGovGrid & 0.08 & 0.28 & $\begin{array}{l}\text { dummy for Democrat governor, divided } \\
\text { legislature }\end{array}$ & (a), various years \\
\hline RGovDiv & 0.19 & 0.39 & $\begin{array}{l}\text { dummy for Republican governor, Democrat } \\
\text { legislature }\end{array}$ & (a), various years \\
\hline DGovDiv & 0.29 & 0.46 & $\begin{array}{l}\text { dummy for Democrat governor, Republican } \\
\text { legislature [omitted category] }\end{array}$ & (a), various years \\
\hline RUnified & 0.14 & 0.35 & $\begin{array}{l}\text { dummy for Republican governor, Republican } \\
\text { legislature }\end{array}$ & (a), various years \\
\hline DUnified & 0.28 & 0.45 & $\begin{array}{l}\text { dummy for Democrat governor, Democrat } \\
\text { legislature }\end{array}$ & (a), various years \\
\hline Turnout (\%) & 0.45 & 0.12 & voter turnout (\%) for last presidential election & (a), various years \\
\hline Origin Year & -3.90 & 9.77 & year state established its SAA - 1969 & various SAA websites \\
\hline BalanceBudg & 1.46 & 0.64 & $\begin{array}{l}\text { categorical }[0-2] \text {, with } 2 \text { indicating strictest } \\
\text { budget rules }\end{array}$ & ACIR (1987) \\
\hline \multicolumn{3}{|c|}{$\begin{array}{l}\text { Term Year 1, Term Year 2, } \\
\text { Term Year } 3\end{array}$} & $\begin{array}{l}\text { dummy for first, second, or third year in the } \\
\text { presidential term (e.g., Second=1 for 2005) }\end{array}$ & \\
\hline \multicolumn{5}{|c|}{$\begin{array}{l}\text { Key: (a) Statistical Abstract of the United States, years as indicated. } \\
\text { (b) US Census website. Www.census.gov } \\
\text { (c) Author's calculations. Data collected from reports of the Current Population Survey published by } \\
\text { the Census for 1970, 1980, 1989, 1990, 1993-2006. Missing values imputed using state-by-state } \\
\text { regressions with predictors: real per capita income, Youth, and the high school graduation rate, and a } \\
\text { time trend. }\end{array}$} \\
\hline
\end{tabular}


Table 2: Results of GMM Estimation of SAA Appropriations, 1969 - 2002.

\begin{tabular}{|c|c|c|c|c|c|c|}
\hline \multirow[b]{2}{*}{ Variable } & \multicolumn{2}{|c|}{ Model 1} & \multicolumn{2}{|c|}{ Model 2} & \multicolumn{2}{|c|}{ Model 3} \\
\hline & coeff. & $\mathbf{Z}$ & coeff. & $\mathbf{Z}$ & coeff. & $\mathbf{z}$ \\
\hline $\mathrm{SAA}_{\mathrm{t}-1}$ & $0.746 * * *$ & 27.48 & $0.639 * * *$ & 17.4 & $0.729 * * *$ & 27.27 \\
\hline Revenue $_{t}$ & 0.101 & 1.31 & $0.175 * *$ & 2.01 & -0.044 & -0.33 \\
\hline Revenue $_{\mathrm{t}-1}$ & 0.059 & 0.88 & $0.186 * *$ & 2.37 & 0.078 & 0.45 \\
\hline Revenue $_{\mathrm{t}-2}$ & -0.054 & -1.26 & $0.062 *$ & 1.80 & $0.124 * * *$ & 3.20 \\
\hline Debt $_{t}$ & -0.029 & -0.86 & -0.046 & -1.49 & -0.037 & -1.09 \\
\hline Debt $_{\mathrm{t}-1}$ & -0.039 & -1.46 & $-0.057^{*}$ & -1.92 & -0.042 & -1.54 \\
\hline Debt $_{t-2}$ & $0.052 * *$ & 1.99 & $0.060 * *$ & 2.11 & $0.052 * *$ & 2.00 \\
\hline $\mathrm{NEA}_{\mathrm{t}}$ & $0.128 * *$ & 2.13 & $0.105^{*}$ & 1.82 & $0.124^{* *}$ & 2.06 \\
\hline $\mathrm{NEA}_{\mathrm{t}-1}$ & -0.058 & -0.89 & -0.044 & -0.75 & -0.062 & -0.97 \\
\hline $\mathrm{NEA}_{\mathrm{t}-2}$ & $0.090 * *$ & 2.48 & $0.114^{* * *}$ & 3.06 & $0.092 * *$ & 2.47 \\
\hline Population & 0.299 & 1.51 & $-0.861 *$ & -1.69 & $0.472 * *$ & 2.45 \\
\hline Density & 0.529 & 0.92 & $6.750 * * *$ & 4.22 & 0.517 & 0.90 \\
\hline Black & 0.205 & 0.07 & -5.331 & -1.39 & 0.832 & 0.27 \\
\hline Other & 0.205 & 0.52 & -0.115 & -0.38 & 0.123 & 0.32 \\
\hline Youth & $-2.649 * * *$ & -2.73 & $-6.775 * * *$ & -4.01 & $-2.851 * * *$ & -3.03 \\
\hline Elders & $-0.191 *$ & -1.8 & -0.168 & -1.25 & $-0.172 *$ & -1.88 \\
\hline College & 0.210 & 0.34 & 0.008 & 1.05 & 0.300 & 0.39 \\
\hline Income & $0.780 * *$ & 2.54 & $0.898 * *$ & 2.53 & 0.336 & 0.95 \\
\hline RGovGrid & $0.090 * *$ & 2.11 & 0.074 & 1.50 & 0.091* & 1.92 \\
\hline DGovGrid & 0.017 & 0.40 & -0.005 & -0.11 & 0.011 & 0.26 \\
\hline RGovDiv & $0.095 * * *$ & 2.65 & $0.083 * *$ & 2.08 & $0.096 * *$ & 2.53 \\
\hline RUnified & 0.033 & 1.41 & -0.010 & -0.28 & 0.026 & 0.99 \\
\hline DUnified & 0.049 & 1.50 & 0.043 & 1.12 & 0.050 & 1.47 \\
\hline Turnout (\%) & -0.164 & -1.33 & -0.125 & -0.87 & -0.146 & -1.19 \\
\hline Year & $-0.023 * *$ & -2.36 & $-0.063 * * *$ & -5.70 & $-0.029 * * *$ & -2.86 \\
\hline Term Year 1 & $-0.049 *$ & -1.96 & $-0.061 * *$ & -2.56 & $-0.052 * *$ & -2.07 \\
\hline Term Year 2 & 0.020 & 0.77 & 0.014 & 0.54 & 0.019 & 0.73 \\
\hline Term Year 3 & 0.012 & 0.35 & 0.015 & 0.47 & 0.012 & 0.38 \\
\hline Origin Year ${ }^{\mathrm{a}}$ & $0.0003 * *$ & 2.24 & 0.0001 & 0.44 & $0.0003 * *$ & 2.36 \\
\hline BalanceBudga & $0.005 *$ & 1.94 & $0.021 * * *$ & 5.63 & $0.006 * *$ & 2.22 \\
\hline State effects ${ }^{\mathrm{a}}$ & omitted & & Yes & & omitted & \\
\hline+ Revenue $_{\mathrm{t}}$ & & & & & 0.110 & 0.84 \\
\hline+ Revenue $_{\mathrm{t}-1}$ & & & & & 0.005 & 0.03 \\
\hline+ Revenue $_{\mathrm{t}-2}$ & & & & & $-0.250 * *$ & -2.41 \\
\hline +Income & & & & & $0.756 * *$ & 2.17 \\
\hline No. of obs. & \multicolumn{2}{|l|}{1521} & \multicolumn{2}{|l|}{1521} & \multicolumn{2}{|l|}{1521} \\
\hline No. of groups & \multicolumn{2}{|c|}{50} & \multicolumn{2}{|c|}{50} & \multicolumn{2}{|c|}{50} \\
\hline Wald (df) & \multicolumn{2}{|c|}{$15560.40(30)$} & \multicolumn{2}{|c|}{$2.45 \times 10^{10}(52)$} & \multicolumn{2}{|c|}{$3.74 \times 10^{10}(52)$} \\
\hline$m_{2}$ & \multicolumn{2}{|c|}{-0.61} & \multicolumn{2}{|c|}{-0.78} & \multicolumn{2}{|c|}{-0.79} \\
\hline Sargan's $S$ & \multicolumn{2}{|c|}{$\chi^{2}(2005)=27.53$} & \multicolumn{2}{|c|}{$\chi^{2}(2005)<0.001$} & \multicolumn{2}{|c|}{$\chi^{2}(2005)<0.001$} \\
\hline
\end{tabular}


Table 3: State Fixed Effects on Changes in SAA Appropriations

\begin{tabular}{|c|c|c|c|c|c|c|c|}
\hline State & coeff. & $\mathbf{z}$ & Location & State & coeff. & $\mathbf{z}$ & Location \\
\hline AK & -0.019 & -1.27 & Education & MT & $-0.038 * * *$ & -3.32 & Independent \\
\hline $\mathrm{AL}$ & -0.016 & -1.43 & Independent & NC & $-0.022 *$ & -1.76 & Culture \\
\hline $\mathrm{AR}$ & $-0.025 * *$ & -2.18 & Culture & ND & -0.004 & -0.47 & Independent \\
\hline $\mathrm{AZ}$ & 0.013 & 0.68 & Independent & $\mathrm{NE}^{\mathrm{a}}$ & & & Independent \\
\hline CA & -0.017 & -0.99 & Independent & $\mathrm{NH}$ & $-0.021 *$ & -1.75 & Culture \\
\hline $\mathrm{CO}$ & $-0.023^{2}$ & -1.76 & Independent & NJ & -0.011 & -0.48 & State \\
\hline $\mathrm{CT}$ & -0.011 & -0.68 & Independent & NM & 0.007 & 0.43 & Culture \\
\hline $\mathrm{DE}$ & -0.008 & -0.41 & State & NV & 0.019 & 0.86 & Culture \\
\hline FL & $-0.052 *$ & -1.73 & State & NY & 0.010 & 0.59 & Independent \\
\hline GA & -0.017 & -1.04 & Governor's office & $\mathrm{OH}$ & -0.018 & -1.62 & Independent \\
\hline $\mathrm{HI}$ & -0.015 & -0.91 & $\begin{array}{l}\text { Accounting \& } \\
\text { General Services }\end{array}$ & OK & -0.005 & -0.40 & Independent \\
\hline IA & -0.009 & -0.82 & Culture & OR & -0.015 & -0.97 & Indep./ Econ. Dev. \\
\hline ID & -0.004 & -0.26 & State & $\mathrm{PA}$ & -0.001 & -0.11 & Governor's office \\
\hline IL & 0.002 & 0.13 & Independent & RI & $-0.026 *$ & -1.80 & Independent \\
\hline IN & 0.014 & 0.70 & Independent & SC & $-0.031^{* *}$ & -2.52 & Independent \\
\hline KS & -0.008 & -0.67 & Independent & SD & -0.015 & -1.36 & Econ. Dev. \\
\hline KY & -0.019 & -1.58 & $\begin{array}{l}\text { Commerce } \\
\text { Cabinet }\end{array}$ & $\mathrm{TN}$ & $-0.026^{* *}$ & -2.53 & Independent \\
\hline LA & -0.011 & -0.86 & Culture & TX & -0.013 & -0.99 & Independent \\
\hline MA & -0.024 & -1.39 & Independent & UT & $-0.023^{*}$ & -1.69 & Econ. Dev. \\
\hline MD & -0.009 & -0.42 & Econ. Dev. & VA & 0.010 & 0.55 & Independent \\
\hline ME & $-0.035^{* * *}$ & -3.27 & Independent & VT & $-0.049 * *$ & -2.04 & Independent \\
\hline MI & 0.009 & 0.73 & Culture & WA & -0.014 & -1.00 & Independent \\
\hline MN & -0.001 & -0.07 & Independent & WI & 0.003 & 0.27 & Independent \\
\hline $\mathrm{MO}$ & -0.014 & -0.99 & Econ. Dev. & WV & -0.019 & -1.60 & Culture \\
\hline MS & -0.017 & -1.54 & Independent & WY & -0.014 & -1.22 & Culture \\
\hline
\end{tabular}


Table 4: Summary of Key Expectations and Results

\begin{tabular}{|c|c|c|c|}
\hline Category & $\begin{array}{l}\text { Expected influence on } \\
\text { appropriations }(+/-/ 0)\end{array}$ & Source & Result \\
\hline \multirow{3}{*}{$\begin{array}{l}\text { Fiscal } \\
\text { pressures }\end{array}$} & Revenues: + & Olsen 2004 & $\begin{array}{l}\text { Only with state fixed } \\
\text { effects }\end{array}$ \\
\hline & $\begin{array}{l}\text { Revenue declines have } \\
\text { larger impact than } \\
\text { revenue gains }\end{array}$ & Lowell 2004 & Yes, with a two-year lag \\
\hline & NEA grants: + & $\begin{array}{l}\text { Hofferbert and } \\
\text { Urice } 1985\end{array}$ & Yes \\
\hline \multirow{3}{*}{$\begin{array}{l}\text { Institutional } \\
\text { context }\end{array}$} & Party control: 0 & Getzner 2002 & $\begin{array}{l}\text { Nonzero effect for some } \\
\text { situations }\end{array}$ \\
\hline & SAA location:,+- & Mulcahy 2002 & No effect observed \\
\hline & SAA age: + & $\begin{array}{l}\text { Hofferbert and } \\
\text { Urice } 1985\end{array}$ & $\begin{array}{l}\text { Only with no state fixed } \\
\text { effects }\end{array}$ \\
\hline \multirow{7}{*}{$\begin{array}{l}\text { Constituency } \\
\text { efficacy }\end{array}$} & Constituency: 0 & $\begin{array}{l}\text { Hofferbert and } \\
\text { Urice } 1985\end{array}$ & $\begin{array}{l}\text { Only for some } \\
\text { demographic groups }\end{array}$ \\
\hline & Education: + & $\begin{array}{l}\text { Lowell 2004, } \\
\text { Lewis and } \\
\text { Rushton } \\
\text { (forthcoming) }\end{array}$ & No effect \\
\hline & Income: + & Noonan 2004 & Yes \\
\hline & Urban population: + & Lowell 2004 & Yes, with state fixed effects \\
\hline & Cultural diversity: - & Rushton 2003 & No effect observed \\
\hline & $\begin{array}{l}\text { Changing constituency } \\
\text { effects over time }\end{array}$ & Lowell 2004 & $\begin{array}{l}\text { Yes, for young, elderly, } \\
\text { black, and density }\end{array}$ \\
\hline & $\begin{array}{l}\text { Negative time trend } \\
\text { (from cultural } \\
\text { diversification) }\end{array}$ & Rushton 2003 & $\begin{array}{l}\text { Yes, but decay remains } \\
\text { after controlling for } \\
\text { demographic changes }\end{array}$ \\
\hline
\end{tabular}

